\title{
Spectroscopic Characterization of Omeprazole and Its Salts
}

\author{
Tomislav Vrbanec, ${ }^{1}$ Primož Šket, ${ }^{2}$ Franci Merzel, ${ }^{2}$ Matej Smrkolj, ${ }^{1}$ and Jože Grdadolnik ${ }^{2}$ \\ ${ }^{1}$ Krka d.d., Novo Mesto, Šmarješka c. 6, SI-8501 Novo Mesto, Slovenia \\ ${ }^{2}$ National Institute of Chemistry, Hajdrihova 19, SI-1000 Ljubljana, Slovenia
}

Correspondence should be addressed to Jože Grdadolnik; joze.grdadolnik@ki.si

Received 9 June 2017; Accepted 24 September 2017; Published 1 November 2017

Academic Editor: Yiannis Sarigiannis

Copyright (c) 2017 Tomislav Vrbanec et al. This is an open access article distributed under the Creative Commons Attribution License, which permits unrestricted use, distribution, and reproduction in any medium, provided the original work is properly cited.

\begin{abstract}
During drug development, it is important to have a suitable crystalline form of the active pharmaceutical ingredient (API). Mostly, the basic options originate in the form of free base, acid, or salt. Substances that are stable only within a certain $\mathrm{pH}$ range are a challenge for the formulation. For the prazoles, which are known to be sensitive to degradation in an acid environment, the formulation is stabilized with alkaline additives or with the application of API formulated as basic salts. Therefore, preparation and characterization of basic salts are needed to monitor any possible salinization of free molecules. We synthesized salts of omeprazole from the group of alkali metals $(\mathrm{Li}, \mathrm{Na}$, and $\mathrm{K})$ and alkaline earth metals $(\mathrm{Mg}$, $\mathrm{Ca})$. The purpose of the presented work is to demonstrate the applicability of vibrational spectroscopy to discriminate between the OMP and OMP-salt molecules. For this reason, the physicochemical properties of 5 salts were probed using infrared and Raman spectroscopy, NMR, TG, DSC, and theoretical calculation of vibrational frequencies. We found out that vibrational spectroscopy serves as an applicable spectroscopic tool which enables an accurate, quick, and nondestructive way to determine the characteristic of OMP and its salts.
\end{abstract}

\section{Introduction}

In drug development, only the most stable crystalline forms of an active substance are suitable for commercial use. In general, active substances can be used in form of an acid, base, or in a form of a salt. Substances, which are stable over a certain $\mathrm{pH}$ range, are a challenge for the development of formulations. Prazoles are susceptible to degradation in an acid environment. Therefore, they are stabilized in the formulation with alkaline additives or administered in the form of basic salts [1]. The preparation and complete characterization of basic salt is needed in the case of direct application of the formulation and for monitoring the potential undesired salt formation. For the pharmaceutical industry, the disposal of stable product-specific solubility and bioavailability is crucial. Preparation of the salt of the active substance in the case of omeprazole makes it possible to affect the stability, solubility, and bioavailability. Vibrational spectroscopy is a very useful technique due to its ability to probe a sample in an accurate, fast, and nondestructible way.
Moreover, the vibrational spectra possess all information of the structure and dynamics of the probed molecule. Raman and infrared of mapping experiments probe a small area of sample and thus check the homogeneity of sample below micrometer (Raman). However, the limitation of applicability of Raman and infrared spectroscopy lays in the necessity to assign the vibrational bands in the corresponding spectrum.

5-Methoxy-2-[[(4-methoxy-3,5-dimethyl-2-pyridinyl)methyl] sulfinyl]- ${ }^{1} \mathrm{H}$-benzimidazole (omeprazole, OMP) is used to treat gastric and duodenal ulcers, erosive esophagitis, gastroesophageal reflux disease, Zollinger-Ellison syndrome, and others [2]. It acts as a proton-pump inhibitor which inhibits gastric acid secretion, that is, irreversibly blocks the enzyme system of hydrogen/potassium adenosine triphosphatase $\left(\mathrm{H}^{+} / \mathrm{K}^{+}\right.$-ATPase $)$in gastric parietal cells. The OMP molecule has a stereochemical center and hence it exists as the $\mathrm{R}$ and $\mathrm{S}$ isomer (Figure 1). Both isomers show activity, but the $\mathrm{S}$ isomer is metabolized more slowly, which results in reproducibly extended release of S-omeprazole [3]. The 
<smiles>COc1ccc2[nH]c(S(C)(=O)=O)nc2c1</smiles><smiles>COc1cc2nc(S(=O)Cc3ncc(C)c(OC)c3C)[nH]c2s1</smiles><smiles></smiles>

(a)<smiles></smiles>

(b)

FIGURE 1: Enantiomers (a) and tautomers (b) of OMP. S (upper left molecule) and R (lower left molecule) enantiomers of OMP. 5-Methoxy OMP (upper right) and 6-methoxy (lower right) tautomers of OMP.

reactive side of the OMP molecule is an acid group in the benzimidazole ring. Therefore, in the preparation of the final form (formulation), various stabilizers are used in order to prevent chemical reaction between excipients and OMP. One of the possibilities to reduce the reactivity of the acid group is a reaction with bases to synthesis an OMP in salt form.

Previous vibrational studies [4] analysed only the principal characteristic peaks of OMP. Similar peaks in infrared spectra were also described in various patents [5-7]. Murakami et al. partially extended peak assignment of the solid-state OMP-Na. The analyses revealed that OMP$\mathrm{Na}$ contains one water molecule in its crystal structure. It was suggested that the water molecule in the OMP-Na probably establishes one hydrogen bond with nitrogen of the imidazole ring and the other with a sulfoxide group. Markovic et al. [8] studied both OMP isomers. By using DSC method, they identified that both optical isomers of OMP-Na are thermodynamically more stable (melting of S isomer at $227^{\circ} \mathrm{C}$ and $\mathrm{R}$ isomer at $229^{\circ} \mathrm{C}$ ) than the OMP in neutral form which melts at $159^{\circ} \mathrm{C}$.

In some cases, vibration spectroscopy may be preferable with respect to other analytical techniques, considering that the vibrational spectra reflect changes in functional groups that appear after salt formation. This can be very helpful in detection of salts in a mixture with OMP. For example, Raman microspectroscopy (mapping) may be utilized in the determination of salt formation on the edges of a specific layer in an OMP pellet. The amount of salts is in general very low and thus under the detection limit for other techniques [9-11].

The presented study will show the ability to monitor these transformations by the application of various types of spectroscopies (infrared, Raman, and NMR) supported by $\mathrm{X}$-ray powder diffraction, DSC, and thermogravimetric measurements. The formation of OMP salts was confirmed by comparing the recorded infrared and NMR spectra with XRPD diffraction patterns. Since we would like to apply only infrared and/or Raman spectroscopy for identification of OMP in salt form, the assignment of specific vibrational peaks that are characteristic for the formation of salt was analysed in detail. The first candidates are the characteristic modes of the benzimidazole ring $(\mathrm{N}-\mathrm{H}, \mathrm{C}=\mathrm{C}-\mathrm{N}$, and $\mathrm{S}-\mathrm{C}=\mathrm{N})$ and $\mathrm{S}=\mathrm{O}$ group.

\section{Materials and Methods}

Omeprazole salts were prepared from the omeprazole purchased from Shouguang Fukang Pharmaceutical. All reactants used were of analytical grade. The alkali salts of omeprazole ( $\mathrm{Na}, \mathrm{K}$, and $\mathrm{Li}$ ) were synthesized by applying a similar procedure. Sodium salt was synthesized by reaction of OMP ( $10 \mathrm{~g}$ ) with a water solution of $\mathrm{NaOH}$ (Aldrich, $1.16 \mathrm{~g}, 25 \mathrm{~mL}$ ). After 5 minutes of vigorous stirring, methylene chloride (Merck) was added $(50 \mathrm{~mL})$ and stirring was continued for the next 15 minutes, after which two phases were separated and the water phase was evaporated to dry matter using a water bath $\left(35^{\circ} \mathrm{C}\right)$. The dry substance was then mixed with $70 \mathrm{~mL}$ of ethyl acetate and stirred under reflux (at $77^{\circ} \mathrm{C}$ ) for the next 30 minutes. After an overnight cooling and resting, the residue was dried under vacuum $\left(40^{\circ} \mathrm{C}\right.$ for $\left.24 \mathrm{~h}\right)$. The final product had a mass of $90.7 \mathrm{~g}$ which correlates with a yield of $85 \%$. Potassium and lithium salt of omeprazole were synthesized in a similar procedure by using $\mathrm{LiOH}$ (Aldrich, $0.207 \mathrm{~g}$ in $40 \mathrm{~mL}$ ) or $\mathrm{KOH}$ (Aldrich, $1.69 \mathrm{~g}$ in $60 \mathrm{~mL}$ ). The yields of OMP-Li was 74\% and of OMP-K was $87 \%$.

The alkaline earth salts of OMP ( $\mathrm{Mg}$ and $\mathrm{Ca}$ ) were synthesized using OMP-Na as a starting material. Anhydrous calcium (Aldrich, 1.16g)/magnesium chloride (Aldrich, $2.12 \mathrm{~g}$ ) was dissolved in distilled water $(20 \mathrm{~mL})$, and the solution was added drop by drop to a water solution of OMP-Na followed by vigorous stirring for 60 minutes The remainder in the flask was filtered, washed up with water, and dried on $40^{\circ} \mathrm{C}$ for $24 \mathrm{~h}$. The yields in case of OMP-Mg and OMPCa reactions were $74 \%$ and $68 \%$, respectively.

The XRPD patterns and NMR spectra of all salts were recorded and compared with those found in literature $[1,5-7,12-14]$ to confirm the formation and purity of prepared salts of omeprazole.

The DSC analysis was performed by Mettler Toledo

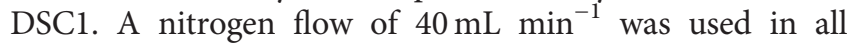
measurements. Samples were analysed in aluminium pans (volume $40 \mu \mathrm{L}$ ) with a punctured cover in a temperature range between $20^{\circ} \mathrm{C}$ and $200^{\circ} \mathrm{C}$ and at a heating rate of 
$10^{\circ} \mathrm{C} \mathrm{min}^{-1}$. Stare Software 11.00 software package was used for data collecting and processing.

Thermogravimetric experiments were measured on the Mettler Toledo TGA/DSC1 instrument. Samples were analysed in aluminium containers with a perforated aluminium lid with a capacity of $100 \mu \mathrm{L}$ in the temperature range from room temperature to $180^{\circ} \mathrm{C}$ with a heating rate of $10^{\circ} \mathrm{C}$ $\mathrm{min}^{-1}$. Stare Software 11.00 software package was used for data collection and processing.

$\mathrm{X}$-ray diffraction intensities were measured on an X-ray diffractometer PHILIPS X'Pert PRO, PANalytical. The diffractometer is equipped with a detector X'celerator and an $\mathrm{X}$-ray tube with a copper anode $\mathrm{k}-\alpha=1.54$. Data processing was done by applying a software package HighScore Plus 3.0e. Samples were recorded in the range between $3^{\circ}$ and $32.5^{\circ}$. The integration time was $100 \mathrm{~s}$, and the step was $0.033^{\circ}$. The patterns were compared with published data using a software package for digitizing named WinDig 2.5.

NMR spectra of solid samples were recorded on Agilent Technologies VNMRS $600 \mathrm{MHz}$ NMR spectrometer equipped with $3.2 \mathrm{~mm}$ NB Double Resonance HX MAS Solids Probe. The ${ }^{1} \mathrm{H}$ MAS and ${ }^{13} \mathrm{C} C \mathrm{CP}$-MAS NMR spectra were externally referenced using adamantane. Samples were spun at the magic angle with 20 and $16 \mathrm{kHz}$ for ${ }^{1} \mathrm{H}$ MAS and ${ }^{13} \mathrm{C}$ CP-MAS NMR spectra, respectively. The proton spectra were acquired using a composite pulse sequence. Repetition delay in all experiments was $5 \mathrm{~s}$. The number of scans was 16. The pulse sequences used for acquiring the ${ }^{13} \mathrm{C}$ spectra were a standard cross-polarization MAS pulse sequences with high-power proton decoupling during acquisition. The repetition delay was $5 \mathrm{~s}$. The number of scans was between 350 and 760. NMR spectra of the liquid samples were recorded on Agilent Technologies DD2 $300 \mathrm{MHz}$ NMR spectrometer, using a $5 \mathrm{~mm}$ ID probe equipped with gradients. The spectra were recorded at $25^{\circ} \mathrm{C}$. Proton chemical shifts were determined relative to tetramethylsilane (TMS).

Raman spectra were recorded using the Raman spectrometer RAMII attached to Vertex 80 infrared spectrometer (BRUKER). The spectrometer was equipped with lasers emitting at $1064 \mathrm{~nm}$ and a LN-Ge diode detector. The spectra were recorded with a laser power of $300 \mathrm{~mW}$, in the spectral region between 3600 and $32 \mathrm{~cm}^{-1}$ with a nominal resolution of $4 \mathrm{~cm}^{-1}$. The final spectrum was a result of averaging of 128 scans. The device operates using a software package OPUS 6.5, which is also used for processing the recorded spectra.

Measurements of infrared spectra were performed by FTIR Vertex 70 spectrometer, manufactured by Bruker. The samples were prepared in the form of $\mathrm{KBr}$ pellets. The spectrometer was equipped with a DLaTGS detector. Recorded spectra are the result of averaging 32 scans in the spectral region between $4000-400 \mathrm{~cm}^{-1}$ with a nominal resolution of $4 \mathrm{~cm}^{-1}$. The spectra were recorded and processed by the application of the OPUS 6.5 software (Bruker).

The calculation of vibrational spectrum of omeprazole was based on density functional theory as implemented in the Vienna Ab initio simulation package (VASP) $[15,16]$. VASP performs an iterative solution of the Kohn-Sham equations in a plane-wave basis; the interaction of the valence electrons with the ionic cores is described within the projector-augmented-wave (PAW) formalism [17]. The cutoff energy value was set to $500 \mathrm{eV}$. The electronic exchange and correlation were described by the gradient-corrected PBE functional proposed by Perdew et al. [18]. The selfconsistency cycle was terminated when the total energies in the next step changed by less than $10^{-6} \mathrm{eV}$ per cell. Brillouin-zone integrations were performed on MonkhorstPack grids [19]. The crystal structure of omeprazole was obtained from the Crystallography Open Database (COD id 7101903) [20]. A corresponding triclinic crystal cell (P1) $\left(a=9.701 \AA, b=10.259 \AA, c=10.694 \AA, \alpha=91.720^{\circ}\right.$, $\beta=112.117^{\circ}$, and $\left.\gamma=115.642^{\circ}\right)$ contains two molecular units. The initial atomic positions (see Supplementary Material available online at https://doi.org/10.1155/2017/6505706) were energy minimized by applying the conjugate gradient algorithm followed by the residual minimization scheme with direct inversion in the iterative subspace (RMM-DIIS) until stopping criterion for forces, Fmax $<10^{-5} \mathrm{eV} / \AA$, was achieved [21]. Vibrational density of states (vDOS) was obtained as a distribution of eigenvalues of the dynamical matrix formed from the force-constant matrix by taking into account periodic boundary conditions. The elements of the force-constant matrix were determined as first derivatives of the forces induced by small ionic displacements, calculated according to the Hellmann-Feynman theorem by using the finite difference method [22]. Assignment of the vibrational spectrum was facilitated by projecting the total vDOS, $g(\omega)$, into partial diatomic vDOS, $g_{\text {bond }}(\omega)$, associated with the stretching vibration of a given chemical bond in the molecule, simply by determining the appropriate relative weight, $w_{\text {bond }}(\omega)$, of the corresponding atomic pair over the entire molecule for a given frequency mode,

$$
g_{\text {bond }}(\omega)=w_{\text {bond }}(\omega) g(\omega) .
$$

As dynamical matrix eigenvectors contain information about individual atomic displacements in a given vibrational mode, we calculate $w_{\text {bond }}(\omega)$ by dividing the sum of the squared displacements along the unit bond direction $\vec{e}_{12}=$ $\left(\vec{r}_{\mathrm{a} 1}-\vec{r}_{\mathrm{a} 2}\right) /\left|\vec{r}_{\mathrm{a} 1}-\vec{r}_{\mathrm{a} 2}\right|$, between atoms $\alpha_{1}$ and $\alpha_{2}$ by the square of the eigenvector,

$$
w_{\text {bond }}(\omega)=\frac{\left|\vec{e}_{12} \cdot \vec{d}_{\mathrm{a} 1}(\omega)\right|^{2}+\left|\vec{e}_{12} \cdot \vec{d}_{\mathrm{a} 2}(\omega)\right|^{2}}{\sum_{\mathrm{a}}\left|\vec{d}_{\mathrm{a}}(\omega)\right|^{2}} .
$$

\section{Results and Discussion}

3.1. Thermogravimetric Analysis. Thermal measurements started by using TGA and DSC techniques were applied to explore polymorphism of omeprazole and its salts. Each form of prepared omeprazole salts showed the loss of mass which is consistent with the release of crystalline and/or surfacebound water (Figure 2). In OMP-K, the loss in mass was observed in one step from $100^{\circ} \mathrm{C}$ to $170^{\circ} \mathrm{C}$ and corresponds to the release of one water molecule. In OMP-Na, the loss in mass was observed in two steps, the first one from $85^{\circ} \mathrm{C}$ 


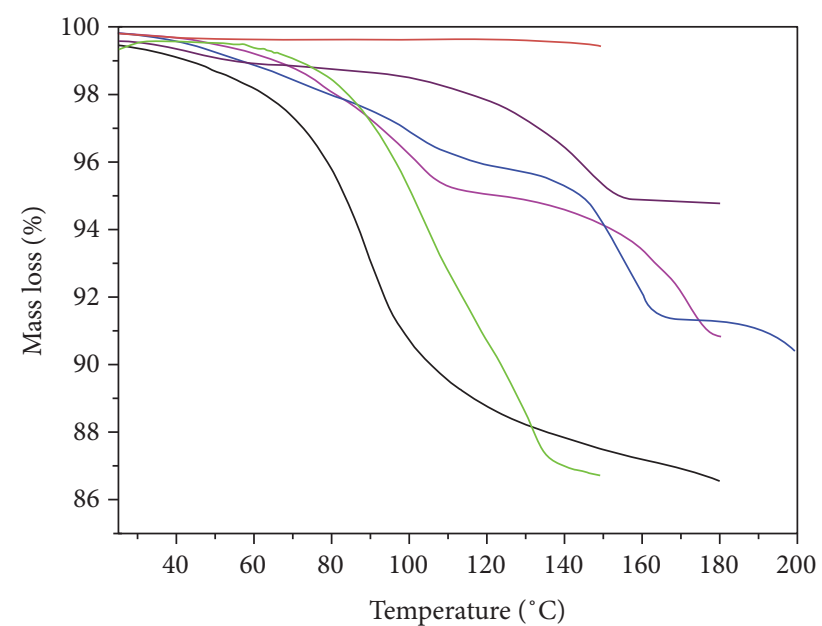

Figure 2: Thermo gravimetrical curves of OMP (red) and five OMP salts (OMP-K (violet), OMP-Na (blue), OMP-Mg (pink), OMP-Li (green), and OMP-Ca (black)).

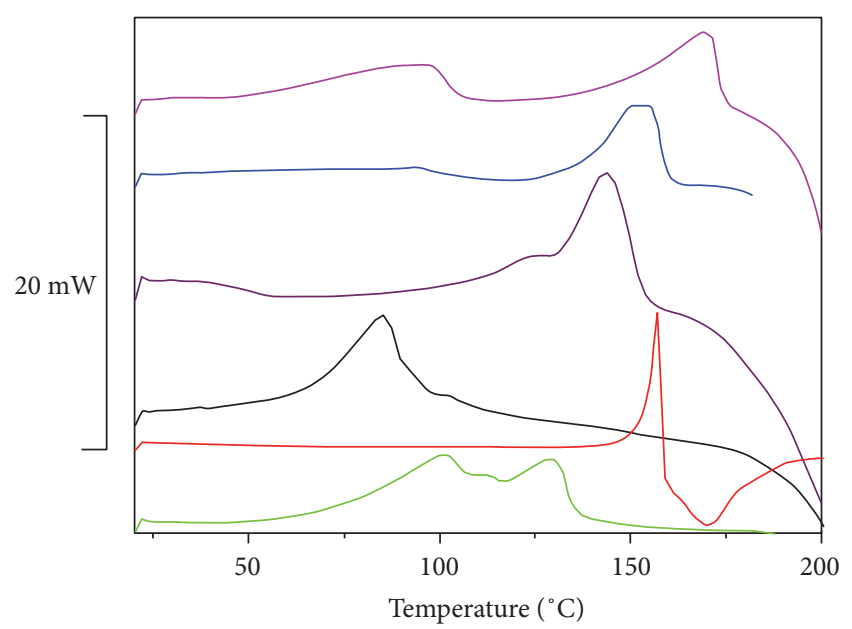

Figure 3: DSC curves of OMP (red) and prepared salts (OMP-K (violet), OMP-Na (blue), OMP-Mg (pink), OMP-Li (green), OMP-Ca (black)). The curves are shifted for clarity.

to $110^{\circ} \mathrm{C}$ and the second one from $120^{\circ} \mathrm{C}$ to $160^{\circ} \mathrm{C}$. Both steps are in the accordance with the release of two water molecules $[5,6,8,23-25]$. In OMP-Mg, the loss in mass in two steps was also observed, from $85^{\circ} \mathrm{C}$ to $105^{\circ} \mathrm{C}$ and from $135^{\circ} \mathrm{C}$ to $170^{\circ} \mathrm{C}$ which is in accordance with the release of two water molecules [12]. In OMP-Ca, the continuous loss in mass was observed from $40^{\circ} \mathrm{C}$ to $150^{\circ} \mathrm{C}$ (loss of three water molecules), while OMP-Li experienced the continuous loss of mass from $70^{\circ} \mathrm{C}$ to $150^{\circ} \mathrm{C}$ (also in accordance with the loss of three water molecules). Thermal analysis showed that all prepared omeprazole salts were in hydrate form.

3.2. Differential Scanning Calorimetry. Characteristic graphs of DSC measurements OMP and its salts are shown in Figure 3. DSC of omeprazole displays only one melting point at $150^{\circ} \mathrm{C}$ after which decomposition occurs, whereas the DSC curves of omeprazole salts are more complex. In the case of

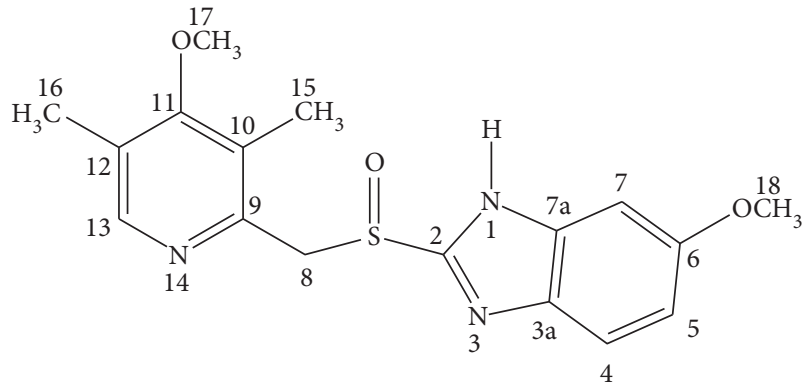

FIGURE 4: OMP with numbered carbon and nitrogen atoms.

OMP-Mg, two melting points were measured (at $100^{\circ} \mathrm{C}$ and $170^{\circ} \mathrm{C}$ ) followed by decomposition. OMP-Na also has two melting points (at $100^{\circ} \mathrm{C}$ and $150^{\circ} \mathrm{C}$ ) again followed by decomposition. The result is in agreement with the thermogravimetric measurements and results from literature [23] where the OMP-Na form A was measured. Potassium salt has only one melting point at $145^{\circ} \mathrm{C}$ followed by decomposition, whereas OMP-Li experiences three melting points (at $100^{\circ} \mathrm{C}, 110^{\circ} \mathrm{C}$, and $125^{\circ} \mathrm{C}$ ) followed by decomposition. Similarly, OMP-Ca has also three melting points (at $58^{\circ} \mathrm{C}, 90^{\circ} \mathrm{C}$, and $100^{\circ} \mathrm{C}$ ) followed by decomposition.

The correlation of results obtained by TGA and DSC is very high and were thus used for clarifying spectroscopic measurements such as DVS and hot-stage in combination with in situ.

3.3. NMR. In order to additionally characterize solid OMP and its salt, we measured ${ }^{1} \mathrm{H}$ MAS and ${ }^{13} \mathrm{C}$ CP-MAS NMR spectra. For assignment of the ${ }^{13} \mathrm{C}$ spectra, we used atom numbering shown in Figure 4. We focused on the expected differences mainly in ${ }^{13} \mathrm{C}$ spectra between various types of OMP (Table 1). Comparison of the proton ${ }^{1} \mathrm{H}$ MAS NMR spectra of solid samples of OMP and all prepared salts revealed that the OMP sample comprises the signal at $13.5 \mathrm{ppm}$ (Figure 5). The signal at this chemical shift is assigned to a proton on the nitrogen atom N1, which is involved in a hydrogen bond. This type of proton is missing in all almost identical proton spectra of OMP salts. That may indicate that salt formation removes the proton attached to $\mathrm{N} 1$ nitrogen.

It is evident from Figure 6 that one of the most prominent differences between omeprazole and its salts in the ${ }^{13} \mathrm{C} \mathrm{CP}$ MAS NMR spectra of solid samples is in the region between $90 \mathrm{ppm}$ and $100 \mathrm{ppm}$, where carbon atom C7 resonates. The rest of OMP ${ }^{13} \mathrm{C}$ spectra were assigned following the data from literature [26]. All spectra presented in Figure 6 correspond to a tautomeric form of 6-metoxy-omeprazole. In contrast to omeprazole where the corresponding $\mathrm{C} 7{ }^{13} \mathrm{C}$ chemical shift is located at $92.0 \mathrm{ppm}$, the other samples of OMP salts show this signal at $98.0 \mathrm{ppm}$. The differences in signal chemical shifts indicate that in samples of OMP salts certain changes appear in the vicinity of the carbon atom $\mathrm{C} 7$, such as the absence of the proton on a nitrogen atom N1.

Another prominent difference between OMP and its salts can be found in the region spanned between $45 \mathrm{ppm}$ and $65 \mathrm{ppm}$. One peak found in the omeprazole spectrum is 
TABLE 1: Carbon chemical shifts (ppm) of OMP and its salts.

\begin{tabular}{|c|c|c|c|c|c|c|}
\hline C atom & OMP & $\mathrm{OMP}-\mathrm{Na}$ & OMP-K & OMP-Li & OMP-Mg & OMP-Ca \\
\hline $\mathrm{C} 15$ & 8.96 & 10.43 & 11.79 & 11.61 & 11.90 & 11.09 \\
\hline $\mathrm{C} 16$ & 12.60 & 12.34 & 13.34 & 14.40 & 13.00 & 13.54 \\
\hline \multirow[t]{4}{*}{ C8, C17, C18 } & 57.81 & 53.75 & 52.78 & 53.35 & 52.55 & 52.39 \\
\hline & - & 58.48 & 59.22 & 60.23 & 58.79 & 54.71 \\
\hline & - & 60.74 & - & - & - & 60.05 \\
\hline & - & - & - & - & - & 61.79 \\
\hline \multirow[t]{2}{*}{$\mathrm{C} 7$} & 92.02 & 99.02 & 98.40 & 97.16 & 97.21 & 96.59 \\
\hline & - & - & - & - & - & 98.67 \\
\hline \multirow[t]{2}{*}{$\mathrm{C} 5$} & 112.94 & 111.31 & 108.39 & 113.21 & 109.31 & 110.29 \\
\hline & & 114.60 & 117.08 & 117.53 & 116.78 & 111.70 \\
\hline $\mathrm{C} 4$ & 121.85 & 125.11 & 124.32 & 126.82 & 124.44 & 116.60 \\
\hline \multirow[t]{3}{*}{$\mathrm{C} 10, \mathrm{C} 12$} & 126.00 & 127.41 & 126.94 & 129.49 & 127.95 & 125.82 \\
\hline & - & - & - & - & - & 127.56 \\
\hline & - & - & - & - & - & 128.98 \\
\hline \multirow[t]{2}{*}{$\mathrm{C} 3 \mathrm{a}-\mathrm{C} 7 \mathrm{a}$} & 136.00 & 139.30 & 139.41 & 139.62 & 137.20 & 137.67 \\
\hline & & & & & & 139.44 \\
\hline \multirow[t]{5}{*}{ C9-C13 } & 150.13 & 147.33 & 146.42 & 147.18 & 141.85 & 144.56 \\
\hline & - & 150.71 & 149.02 & - & 147.15 & 146.59 \\
\hline & - & 154.30 & 150.59 & - & 149.46 & 147.78 \\
\hline & - & - & - & - & - & 149.47 \\
\hline & - & - & - & - & - & 151.29 \\
\hline \multirow[t]{2}{*}{ C2-C6 } & 158.05 & 158.24 & 153.32 & 155.48 & 153.66 & 153.63 \\
\hline & - & - & - & 157.18 & 156.59 & 157.868 \\
\hline \multirow[t]{2}{*}{ C11 } & 164.41 & 164.51 & 163.05 & 165.29 & 164.01 & 159.90 \\
\hline & - & - & 164.12 & - & - & 164.22 \\
\hline
\end{tabular}
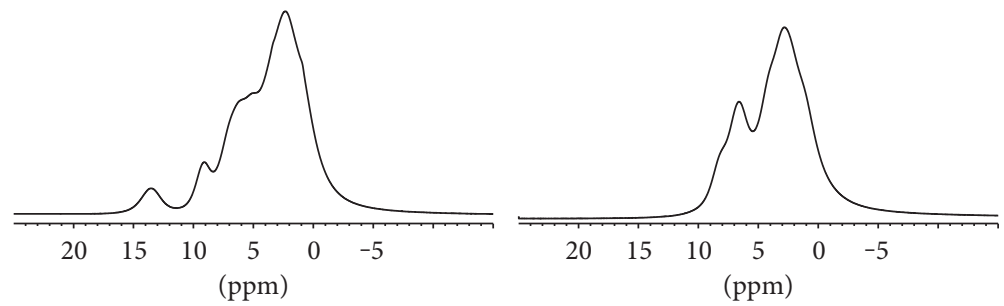

Figure 5: Left spectrum: ${ }^{1} \mathrm{H}$ MAS spectrum of OMP; right spectrum: ${ }^{1} \mathrm{H}$ MAS spectrum of OMP-Na.

evidently multiplied in the salt spectra. This splitting may be connected to the changes in the environment of carbon atoms C8, C17, and C18 of OMP during salt formation, when the cation comes in the vicinity of an OMP molecule.

3.4. Vibrational Analysis. To get a better view on the assignment of OMP vibrational spectrum (Figure 7), the OMP molecule is divided into four fragments. The first fragment is a substituted pyridine ring, the second one is a benzimidazole fragment, and the third one is a C-SO-C bridge. The fourth fragment consists of various methoxy groups. Each and every one of the fragments aforementioned is already assigned in literature [27-30]. Although the band frequencies of fragments may slightly differ from one found in the vibrational spectra, they serve as a relevant guide for band assignment in the spectra of OMP. Band frequencies of band in infrared and Raman spectrum of OMP are tabulated and described in Table 2.

Considering that prior analyses have already determined that the absence of the $\mathrm{NH}$ group is the main factor in salt formation, most of the attention will be given to extract vibrations connected to this group. NH stretching in infrared spectrum is usually visible as a medium intensity band in the range between 3500 and $3200 \mathrm{~cm}^{-1}$. However, the $\mathrm{NH}$ group from the benzimidazole part of the molecule is a strong proton donor, which may participate in hydrogen bonds with various types of proton acceptors which means that $\mathrm{NH}$ stretching frequency would redshift with respect to the 


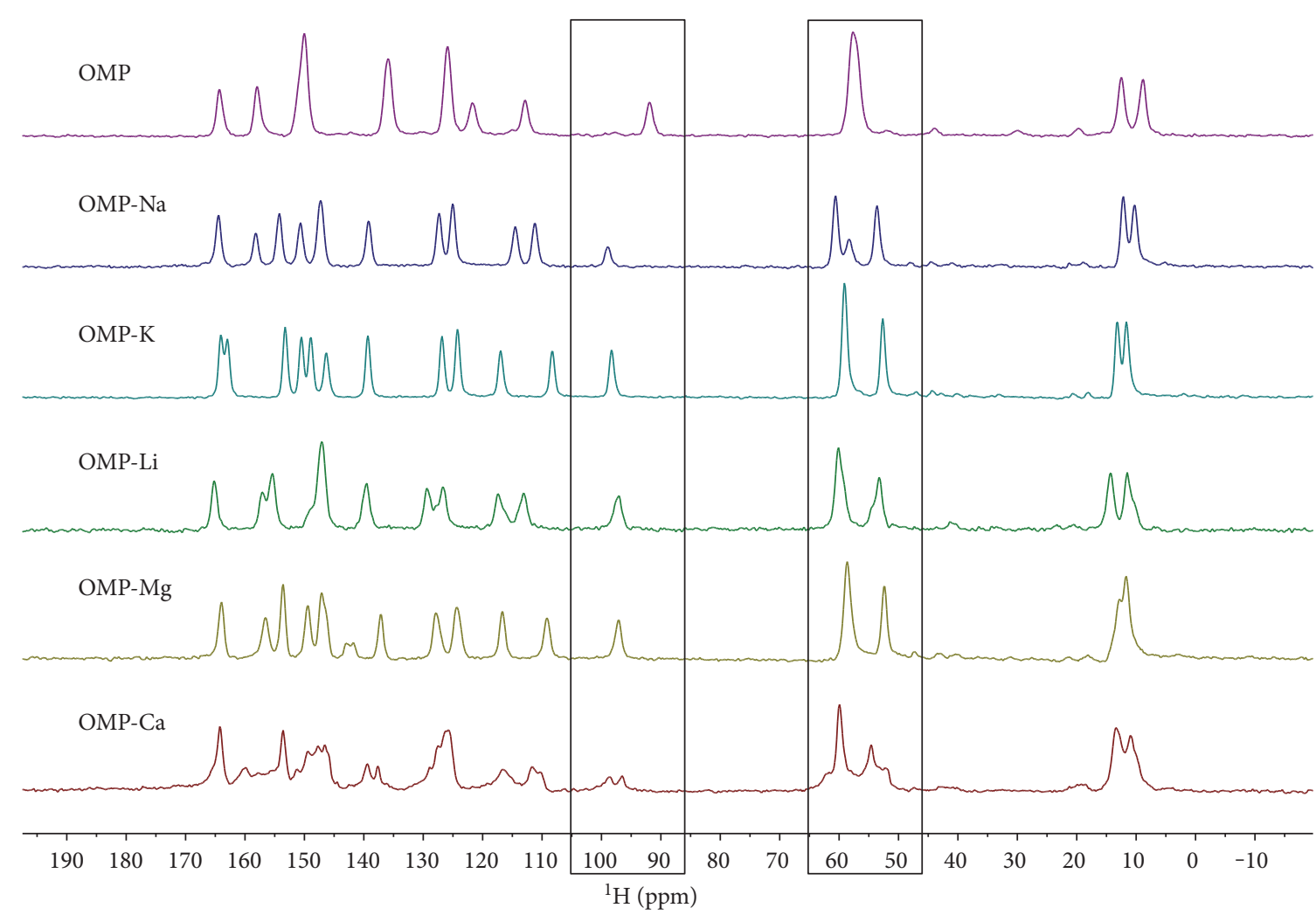

Figure 6: Comparison of ${ }^{13} \mathrm{C}$ CP-MAS NMR spectra of solid samples of OMP and OMP salts.

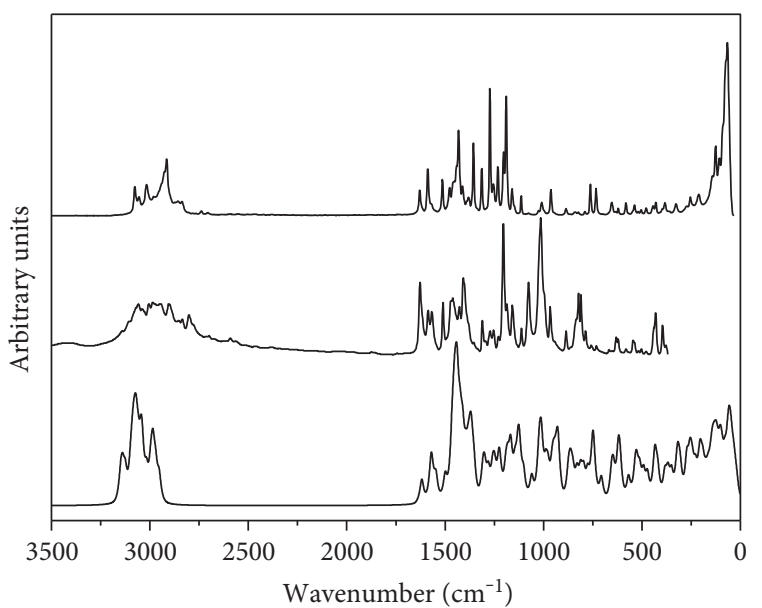

Figure 7: Raman (upper), infrared (middle), and calculated (lower) spectrum of a solid-state OMP.

strength of the established hydrogen bond. A formation of hydrogen bonds also broadens the $\mathrm{NH}$ vibrational band. Therefore, the NH stretching vibration can be found in the infrared spectrum of OMP as a broad band near $2930 \mathrm{~cm}^{-1}$. Another characteristic band for NH group is $\mathrm{NH}$ deformation, which is located near $1587 \mathrm{~cm}^{-1}$. This type of vibration is rarely strictly localized. In the case of OMP, it is coupled with $\mathrm{C}-\mathrm{C}$ stretching and $\mathrm{CH}$ deformations. The coupling reduces the applicability of this type of vibrations for confirmation of the presence of pure OMP.
For the complete assignment of the vibrational spectra of OMP, we used characteristic spectra of particular fragments, which can be found in the molecule. Assignment of key vibrations was checked by calculation (Table 3). Figure 8 presents the most significant vibrations in the calculated spectra of OMP.

By general comparison of infrared and Raman spectra of all five prepared salts, we can conclude that they are structurally very similar with a few exceptions.

Raman and infrared spectra of OMP and all 5 prepared salts in solid state are shown in Figure 9.

Tables with assigned bands for OMP in Raman and infrared spectra were used to support the determination of specificity of individual spectra of salts (Tables 4 and 5).

Although the vibrational spectra of OMP and its salts are very similar, particular differences can be used for the accurate determination of the sample composition. Since all salts are in the form of crystal hydrates, it is that the $\mathrm{NH}$ stretching band will be masked by the broad $\mathrm{OH}$ stretching band of hydrating water. However, OMP has specific Raman bands of medium and medium-weak intensity at $1630 \mathrm{~cm}^{-1}(\mathrm{CH}$ deformation, CC stretching) and $1512 \mathrm{~cm}^{-1}(\mathrm{CH}+\mathrm{NH}$ deformation) that are absent in the spectra of salts. On the other hand, all five prepared salts have characteristic bands of medium intensity at $3006 \mathrm{~cm}^{-1}-2980 \mathrm{~cm}^{-1}(\mathrm{CH}$ stretching $(\mathrm{BI}, \mathrm{P}))$ and at $1364 \mathrm{~cm}^{-1}(\mathrm{C} 4 \mathrm{H}+\mathrm{C} 5 \mathrm{H}$ deformation).

Bands of the highest intensity in the range between 1300 and $1100 \mathrm{~cm}^{-1}$ are partly overlapped; therefore, the identification of specific salts is unlikely just by analysing the 
TABLE 2: Peak frequencies of bands in infrared and Raman spectrum of OMP.

\begin{tabular}{|c|c|c|}
\hline $\operatorname{IR}\left(\mathrm{cm}^{-1}\right)$ & $\begin{array}{l}\text { Raman } \\
\left(\mathrm{cm}^{-1}\right)\end{array}$ & Assignation \\
\hline$\sim 3070$ (shift) & 3076 & $\mathrm{CH}$ stretching $(\mathrm{BI}, \mathrm{P})$ \\
\hline \multirow[t]{2}{*}{3057} & 3055 & $\mathrm{CH}$ stretching $(\mathrm{BI}, \mathrm{P})$ \\
\hline & 3016 & $\mathrm{CH}$ stretching $(\mathrm{BI}, \mathrm{P})$ \\
\hline 2984 & 2981 & $\mathrm{CH}_{3}(\mathrm{M})$ stretching asymmetric \\
\hline 2972 & $\sim 2968$ (sh) & $\mathrm{CH}_{3}(\mathrm{M})$ stretching asymmetric \\
\hline 2944 & 2954 & $\mathrm{CH}_{3}(\mathrm{M})$ stretching asymmetric \\
\hline$\sim 2930$ & Covered & $\mathrm{NH}$ stretching vibration \\
\hline 2904 & 2915 & $\mathrm{CH}_{3}$ stretching asymmetric \\
\hline 2854 & 2857 & $\mathrm{CH}_{3}(\mathrm{M})$ stretching symmetric \\
\hline 2835 & 2837 & $\mathrm{CH}_{3}$ stretching symmetric \\
\hline 1629 & 1629 & $\begin{array}{l}\text { QS }(\mathrm{P}), \mathrm{CH} \text { deformation, } \\
\text { CC stretching }(\mathrm{P}, \mathrm{BI})\end{array}$ \\
\hline 1587 & 1588 & $\begin{array}{l}\mathrm{CH}+\mathrm{NH} \text { deformation, } \\
\mathrm{CC} \text { stretching }(\mathrm{BI})\end{array}$ \\
\hline 1568 & 1569 & $\begin{array}{l}\text { QS }(\mathrm{P}), \mathrm{CH} \text { deformation, } \\
\text { CC stretching }(\mathrm{P}, \mathrm{BI})\end{array}$ \\
\hline 1512 & 1514 & $\mathrm{CH}+\mathrm{NH}$ deformation (BI) \\
\hline $1470(\mathrm{sh})$ & 1477 & $\begin{array}{c}\text { SCS }(\mathrm{P}), \mathrm{CH}(\mathrm{B}), \mathrm{NH} \text { deformation, } \\
\text { N3C2 stretching }\end{array}$ \\
\hline 1462 & 1460 & $\begin{array}{c}\mathrm{CH}_{3} \text { deformation }(\mathrm{M}) \\
\mathrm{NH}+\mathrm{CH} \text { deformation }(\mathrm{BI})\end{array}$ \\
\hline 1428 & 1432 & SCS (P), $\mathrm{CH}_{3}$ deformation symmetric \\
\hline 1410 & 1412 & $\begin{array}{c}\mathrm{NH}+\mathrm{CH} \text { deformation }(\mathrm{BI}) \\
\mathrm{CH} \text { deformation }(\mathrm{P})\end{array}$ \\
\hline 1356 & 1356 & $\mathrm{NH}+\mathrm{C} 4 \mathrm{H}+\mathrm{C} 5 \mathrm{H}$ deformation $(\mathrm{BI})$ \\
\hline 1312 & 1314 & $\mathrm{CH}$ deformation, $\mathrm{R}-\mathrm{O}-\mathrm{CH}_{3}$ stretching \\
\hline 1293 & & $\mathrm{R}-\mathrm{O}-\mathrm{CH}_{3}$ stretching \\
\hline 1273 & 1273 & $\mathrm{NH}+\mathrm{CH}$ deformation symmetric $(\mathrm{BI})$ \\
\hline 1253 & 1255 & $\mathrm{NH}+\mathrm{CH}$ deformation symmetric $(\mathrm{BI})$ \\
\hline 1231 & 1232 & $\mathrm{NH}+\mathrm{CH}$ deformation asymmetric $(\mathrm{BI})$ \\
\hline 1206 & 1203 & $\mathrm{NH}+\mathrm{CH}$ deformation symmetric (BI) \\
\hline 1188 & 1190 & $\mathrm{NH}+\mathrm{CH}$ deformation symmetric (BI) \\
\hline 1160 & 1160 & $\mathrm{CH}$ deformation asymmetric \\
\hline 1113 & 1113 & $\mathrm{CH}$ deformation asymmetric \\
\hline 1077 & 1076 & $\mathrm{NH}$ deformation (BI), $\mathrm{CH}_{3}(\mathrm{M})$ \\
\hline 1014 & 1009 & $\mathrm{~S}=\mathrm{O}$ stretching vibration \\
\hline 967 & 963 & $\mathrm{CH}$ deformation $(\mathrm{BI})$ \\
\hline 885 & 886 & $\mathrm{CH}$ wagging \\
\hline 835 & 842 & $\mathrm{CH} 3$ rocking of methoxy group \\
\hline 822 & 823 & QIPB (P) \\
\hline 810 & 790 & $\mathrm{CH} 3$ rocking ip \\
\hline 787 & & $\mathrm{CH} 3$ rocking ip \\
\hline 759 & 762 & $\mathrm{CH}$ wagging (IM) \\
\hline 732 & 733 & $\mathrm{CH}$ wagging $(\mathrm{B})$ \\
\hline 667 & 653 & $\mathrm{NH}$ wagging (BI) \\
\hline 631 & 635 & S-C stretching sulfoxide chain \\
\hline 621 & 620 & QIPB (P), ring deformation \\
\hline 582 & 582 & $\mathrm{CH}+\mathrm{NH}$ wagging (BI) \\
\hline
\end{tabular}

TABLE 2: Continued.

\begin{tabular}{lcc}
\hline IR $\left(\mathrm{cm}^{-1}\right)$ & $\begin{array}{c}\text { Raman } \\
\left(\mathrm{cm}^{-1}\right)\end{array}$ & Assignation \\
\hline 546 & $546(\mathrm{sh})$ & oop ring deformation \\
535 & 538 & oop ring deformation \\
518 & 519 & oop ring deformation \\
502 & 504 & oop ring deformation \\
478 & 479 & oop ring deformation \\
& 444 & R-O-CH3 deformation (M) \\
& 429 & Ring deformation (BI) \\
& 382 & QOOPB (P) \\
& 327 & CH wagging asymmetric (BI) \\
& 254 & CH wagging \\
& 212 & Phonon vibration \\
& 142 & Phonon vibration \\
& 124 & Phonon vibration \\
& 104 & Phonon vibration \\
& 87 & Phonon vibration \\
72 & Phonon vibration \\
66 &
\end{tabular}

BI: benzimidazole; P: pyridine; M: methoxy group; IM: imidazole; QS: quadrant stretch; SCS: semi-circle stretch; oop: out-of-plane; ip: in-plane; QIPB: quadrant in-plane bend; QOOPB: quadrant out-of-plane bend.

TABLE 3: Calculated stretching and deformation modes of OMP polar groups.

\begin{tabular}{lc}
\hline Group & Frequency $\left(\mathrm{cm}^{-1}\right)$ \\
\hline C-OCH3 (pyridine) & $1423,1181,1013$ \\
C-OCH3 & $1442,1060,988$ \\
N=C-C-CH3 & $1547,1411,1250$ \\
HN-C-S & $3015,1570,1411,1182$ \\
N=C-S & 1411,1182 \\
S=O & $978,618,422,381$ \\
\hline
\end{tabular}

aforementioned wavenumber range. By looking at infrared spectra, we come to the similar conclusion as in the case of Raman spectra. OMP spectrum clearly differs from the spectra of salts by the appearance of medium intensity bands at 1514 and $1356 \mathrm{~cm}^{-1}(\mathrm{CH}+\mathrm{NH}$ deformation (BI) and $\mathrm{NH}+\mathrm{C} 4 \mathrm{H}+\mathrm{C} 5 \mathrm{H}$ deformation (BI)), which are absent in salts. On the other hand, salts have a very specific peak at $1364 \mathrm{~cm}^{-1}(\mathrm{C} 4 \mathrm{H}+\mathrm{C} 5 \mathrm{H}$ deformation $(\mathrm{BI}))$ of weaker intensity, which is absent in the spectrum of OMP. For specific distinction of each individual salt, we have to use the complementarity property of infrared and Raman spectroscopy with a comparison of more characteristic bands to determine specific OMP salt.

Specific OMP-K spectrum is a strong and narrow band at $3600 \mathrm{~cm}^{-1}$ in infrared spectrum (loosely hydrogen-bonded $\mathrm{OH}, \mathrm{OH}$ stretching vibration of absorbed water molecules) and a medium intense band at $1400 \mathrm{~cm}^{-1}$ ( $\mathrm{CH}$ deformation). 

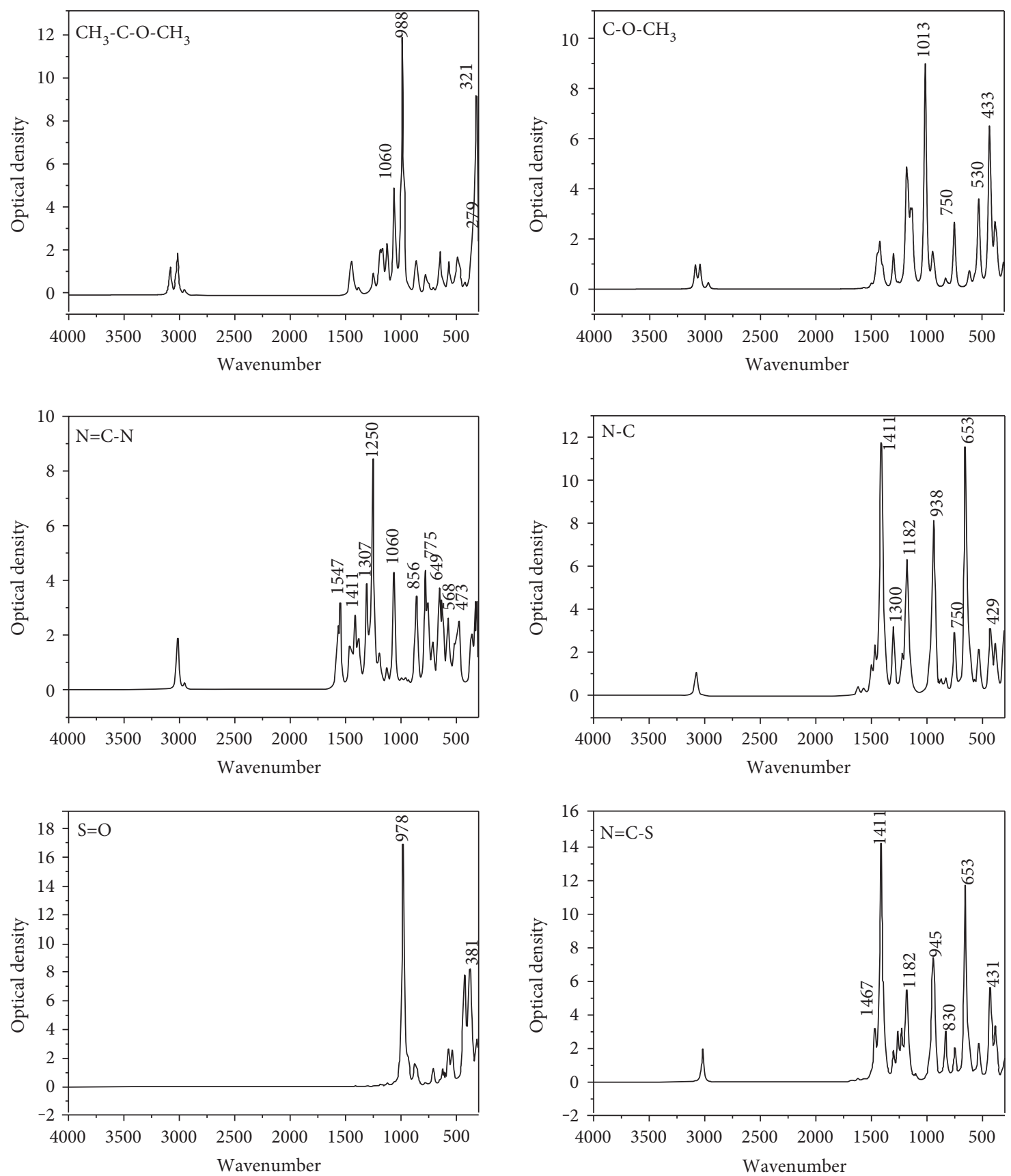

Figure 8: Calculated bands of selected omeprazole functional groups. These bands are taken from the calculation of the optimised OMP molecule. The whole calculated spectrum is presented in Figure 7.

The latter one can be used for identification of the presence of OMP-K salt. OMP-Na is characterized in infrared spectrum by an especially intense and for $\mathrm{OH}$ stretching at $3600-3100 \mathrm{~cm}^{-1}$ unusually narrow band. Raman spectrum bands at $1242 \mathrm{~cm}^{-1}\left(\mathrm{CH}\right.$ deformation) and at $655 \mathrm{~cm}^{-1}$ (S-C stretching) can be used for identification. Raman spectrum of OMP-Ca salts exhibits medium weak intensity band at $990 \mathrm{~cm}^{-1}$ ( $\mathrm{S}=\mathrm{O}$ stretching) that can be used for salt characterization, while in the infrared spectrum characteristic bands at $1396 \mathrm{~cm}^{-1}$ and $1023 \mathrm{~cm}^{-1}$ (-CH deformation / $\mathrm{S}=\mathrm{O}$ stretching) individualize this salt.
In the same manner, OMP-Li is best described by Raman bands with strong and medium intensity which are located at $1190 \mathrm{~cm}^{-1}$ and $628 \mathrm{~cm}^{-1}$ (CH deformation, S-C stretching). Infrared spectrum medium intensity band at $1386 \mathrm{~cm}^{-1} \mathrm{can}$ be used for salt determination.

Infrared spectrum of OMP-Mg contains less specific information. The most applicable are bands at 1410, 1230, and $637 \mathrm{~cm}^{-1}$. Raman spectrum contains partially overlapped band of medium intensity at $2928 \mathrm{~cm}^{-1}$ (CH stretching) and a very intense band at $1253 \mathrm{~cm}^{-1}$ (CH symmetric deformation). There are also two highly specific bands at 1002 and 


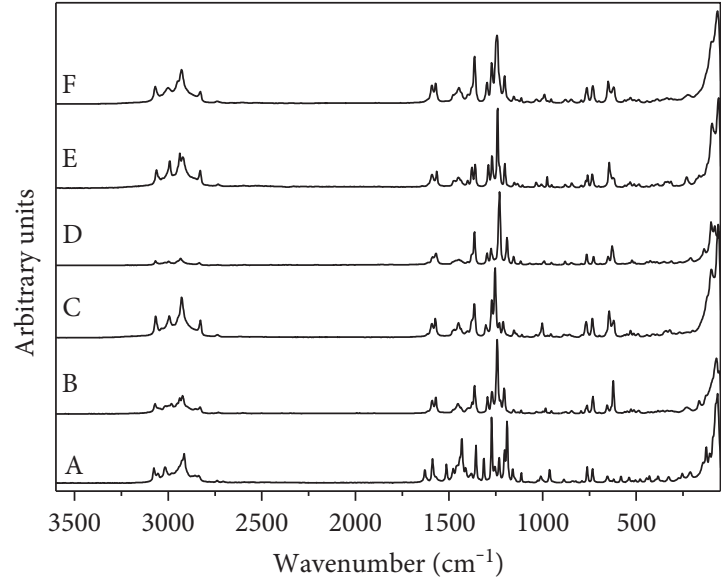

(a)

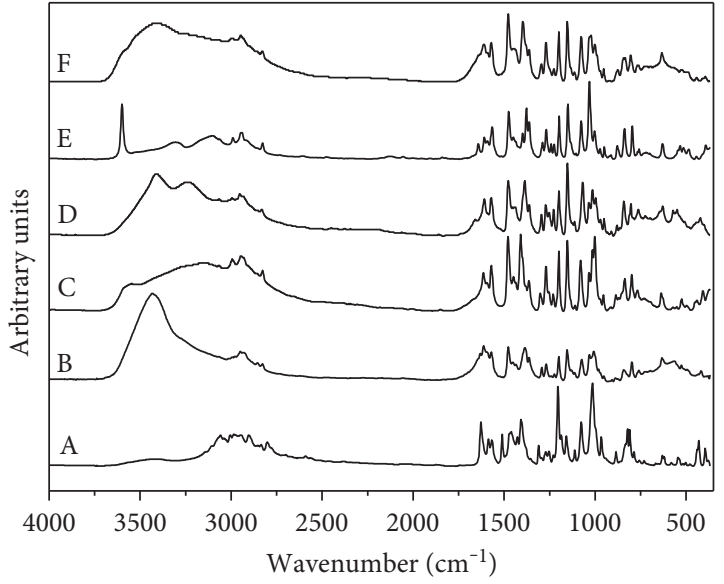

(b)

Figure 9: Raman (a) and infrared (b) spectra of OMP and prepared salts in solid state. (A) OMP, (B) OMP-Na, (C) OMP-Mg, (D) OMP-Li, (E) OMP-K, and (F) OMP-Ca.

TABLE 4: Assignment of characteristic vibrations in infrared spectra of OMP and its salts.

\begin{tabular}{|c|c|c|c|c|c|c|}
\hline Vibration & OMP & OMP-Li & $\mathrm{OMP}-\mathrm{Na}$ & OMP-K & OMP-Mg & OMP-Ca \\
\hline \multirow{2}{*}{$\mathrm{O}-\mathrm{H}$, stretching, $\mathrm{H}$-bonded } & \multirow{2}{*}{-} & 3416 & \multirow{2}{*}{3434} & 3316 & 3543 & \multirow{2}{*}{3406} \\
\hline & & 3241 & & 3109 & 3156 & \\
\hline $\mathrm{O}-\mathrm{H}$ stretching, free & - & - & - & 3600 & - & - \\
\hline $\mathrm{CH}$, stretching $(\mathrm{BI}, \mathrm{P})$ & $\sim 3070$ & 3063 & 3063 & 3062 & 3063 & 3063 \\
\hline $\mathrm{CH}_{3}(\mathrm{M})$, stretching & 2944 & 2935 & 2930 & 2947 & 2930 & 2947 \\
\hline $\mathrm{NH}$, stretching & $\sim 2930$ & - & - & - & - & - \\
\hline QS (P), CH deformation, CC stretching (P, BI) & 1629 & 1608 & 1613 & 1608 & 1613 & 1613 \\
\hline $\mathrm{CH}+\mathrm{NH}$ deformation, $\mathrm{CC}$ stretching $(\mathrm{BI})$ & 1587 & - & - & - & - & - \\
\hline CC stretching $(\mathrm{BI})$ & - & 1591 & 1591 & 1591 & 1591 & 1591 \\
\hline QS (P), CH deformation, CC stretching (P, BI) & 1568 & 1571 & 1570 & 1566 & 1571 & 1571 \\
\hline $\mathrm{CH}+\mathrm{NH}$ deformation $(\mathrm{BI})$ & 1512 & - & - & - & - & - \\
\hline SCS (P), CH (B), NH deformation, N3C2 stretching & 1470 (shift) & 1477 & 1477 & 1475 & 1477 & 1477 \\
\hline $\mathrm{NH}+\mathrm{CH}$ deformation $(\mathrm{BI}), \mathrm{CH}$ deformation $(\mathrm{P})$ & 1410 & - & - & - & - & - \\
\hline $\mathrm{CH}$ deformation $(\mathrm{P})$ & - & 1386 & 1384 & 1400 & 1410 & 1396 \\
\hline $\mathrm{NH}+\mathrm{CH}$ deformation symmetric $(\mathrm{BI})$ & 1273 & - & - & - & - & - \\
\hline $\mathrm{CH}$ deformation $(\mathrm{BI})$ & - & 1270 & 1270 & 1270 & 1270 & 1270 \\
\hline $\mathrm{NH}+\mathrm{CH}$ deformation symmetric $(\mathrm{BI})$ & 1253 & - & - & - & - & - \\
\hline $\mathrm{CH}$ deformation (BI) & - & 1252 & 1242 & 1242 & 1252 & 1252 \\
\hline $\mathrm{NH}+\mathrm{CH}$ deformation symmetric $(\mathrm{BI})$ & 1231 & - & - & - & - & - \\
\hline $\mathrm{CH}$ deformation (BI) & - & 1228 & 1225 & 1225 & 1230 & 1224 \\
\hline $\mathrm{NH}+\mathrm{CH}$ deformation symmetric $(\mathrm{BI})$ & 1206 & - & - & - & - & - \\
\hline $\mathrm{CH}$ deformation (BI) & - & 1200 & 1200 & 1200 & 1200 & 1200 \\
\hline $\mathrm{NH}+\mathrm{CH}$ deformation symmetric $(\mathrm{BI})$ & 1188 & - & - & - & - & - \\
\hline \multirow{3}{*}{$\mathrm{S}=\mathrm{O}$ stretching vibration } & \multirow{3}{*}{1014} & 1035 & 1031 & 1031 & 1034 & 1031 \\
\hline & & 1015 & 1008 & - & 1015 & 1023 \\
\hline & & 998 & - & 1003 & 1002 & 1002 \\
\hline $\mathrm{CH}$ deformation (BI) & 967 & 950 & 950 & 950 & 950 & 950 \\
\hline \multirow{2}{*}{ S-C stretching } & 631 & 628 & 633 & 630 & 637 & 634 \\
\hline & 621 & - & - & - & - & - \\
\hline
\end{tabular}


TABle 5: Description and comparison of specific vibrations in Raman spectra of OMP and its salts.

\begin{tabular}{|c|c|c|c|c|c|c|}
\hline Vibration & OMP & OMP-Li & OMP-Na & OMP-K & OMP-Mg & OMP-Ca \\
\hline $\mathrm{O}-\mathrm{H}$, stretching, $\mathrm{H}$-bond & - & - & - & - & - & - \\
\hline $\mathrm{O}-\mathrm{H}$, stretching, free & - & - & - & - & - & - \\
\hline \multirow{2}{*}{$\mathrm{CH}$, stretching $(\mathrm{BI}, \mathrm{P})$} & 3076 & 3068 & 3070 & 3062 & 3066 & 3069 \\
\hline & 3016 & 2994 & 2981 & 2991 & 2995 & 3000 \\
\hline $\mathrm{CH}_{3}$ stretching, symmetric & 2837 & 2834 & 2830 & 2830 & 2830 & 2830 \\
\hline NH. stretching & Overlapped & - & - & - & - & - \\
\hline QS (P), CH deformation, CC stretching (P, BI) & 1629 & 1589 & 1592 & 1592 & 1592 & 1592 \\
\hline $\mathrm{CH}+\mathrm{NH}$ deformation, $\mathrm{CC}$ stretching $(\mathrm{BI})$ & 1588 & 1570 & 1572 & 1565 & 1572 & 1572 \\
\hline $\mathrm{CH}+\mathrm{NH}$ deformation $(\mathrm{BI})$ & 1514 & - & - & - & - & - \\
\hline SCS (P), $\mathrm{CH}_{3}$ deformation symmetric & 1432 & 1450 & 1454 & 1450 & 1450 & 1446 \\
\hline $\mathrm{NH}+\mathrm{C} 4 \mathrm{H}+\mathrm{C} 5 \mathrm{H}$ deformation (BI) & 1356 & - & - & - & - & - \\
\hline $\mathrm{CH}$ deformation $(\mathrm{BI})$ & - & 1364 & 1364 & 1364 & 1364 & 1364 \\
\hline $\mathrm{NH}+\mathrm{CH}$ deformation symmetric $(\mathrm{BI})$ & 1273 & - & - & - & - & - \\
\hline $\mathrm{CH}$ deformation (BI) & - & 1274 & 1273 & 1270 & 1272 & 1273 \\
\hline $\mathrm{NH}+\mathrm{CH}$ deformation symmetric $(\mathrm{BI})$ & 1255 & - & - & - & - & - \\
\hline $\mathrm{CH}$ deformation $(\mathrm{BI})$ & - & 1230 & 1242 & 1241 & 1253 & 1243 \\
\hline $\mathrm{NH}+\mathrm{CH}$ deformation symmetric $(\mathrm{BI})$ & 1232 & - & - & - & - & - \\
\hline $\mathrm{CH}$ deformation $(\mathrm{BI})$ & - & 1190 & 1225 & 1229 & 1231 & 1229 \\
\hline $\mathrm{NH}+\mathrm{CH}$ deformation symmetric $(\mathrm{BI})$ & 1203 & - & - & - & - & - \\
\hline $\mathrm{CH}$ deformation (BI) & - & - & 1206 & 1201 & 1211 & 1203 \\
\hline $\mathrm{NH}+\mathrm{CH}$ deformation symmetric $(\mathrm{BI})$ & 1190 & - & - & - & - & - \\
\hline $\mathrm{S}=\mathrm{O}$ stretching vibration & 1009 & 992 & 985 & 1006 & 1002 & 990 \\
\hline $\mathrm{CH}$ deformation (BI) & 963 & 954 & 954 & 954 & 954 & 954 \\
\hline \multirow{2}{*}{ S-C stretching } & 653 & 650 & 655 & 644 & 644 & 649 \\
\hline & 635 & 628 & 623 & 620 & 620 & 620 \\
\hline
\end{tabular}

$644 \mathrm{~cm}^{-1}$, but they are of weaker intensity and therefore would be poorly visible in the multicomponent mixture.

\section{Conclusions}

NMR and XRPD methods were used to confirm OMP salt formation by spectra/diffractogram analyses and comparisons with patent data. By comparing ${ }^{1} \mathrm{H}$ MAS NMR spectra of OMP and salts, the absence of a signal at $13.5 \mathrm{ppm}$ in the latter has been attributed to the deprotonation of nitrogen in salts. Furthermore, the comparison of ${ }^{13} \mathrm{C}$ CP-MAS NMR spectra of solid samples of OMP and its salts showed the shift of signal at $92.0 \mathrm{ppm}$ which is assigned to the atom C7 in OMP to 98.0 ppm in salt spectra. This shift may be initiated by structural changes in the vicinity of the C7 atom. Sodium, magnesium, and calcium salts were additionally compared and confirmed by XRPD technique (patent data comparison). Potassium and lithium salts had their first description by using the XRPD technique.

Thermal techniques (TGA and DSC) were used to test the solid-state properties of prepared salts. The results showed consistent phase transitions in all salts with the exception of OMP base which stayed unchanged during the whole cycle up to the melting point. We showed that all salts exhibit hydrate form formation.
We assigned infrared and Raman spectra by the application of already assigned model molecules and quantum calculation of vibrational frequencies. It has been confirmed that salt formations occur by hydrogen cation cleavage from $\mathrm{N}-\mathrm{H}$ bond on benzimidazole ring (absence of bands on 1514 and $582 \mathrm{~cm}^{-1}$ in Raman spectra of salts) and electron delocalisation in sulfoxide chain (bands in the region between $1009 \mathrm{~cm}^{-1}$ and $1016 \mathrm{~cm}^{-1}$ and between 660 and $600 \mathrm{~cm}^{-1}$ ). We found several distinct bands which are characteristic for a particular formation of different OMP salts. Therefore, we have shown that both infrared and Raman spectroscopy are relevant techniques to determine the presence of particular salts in more complex mixtures.

\section{Conflicts of Interest}

The authors declare that there is no conflict of interest regarding the publication of this paper.

\section{References}

[1] M. Hickey and M. Peterson, "Novel omeprazole forms and related methods," Patent: US 2006/0160783 A1, 2006.

[2] T. Lind, C. Cederberg, G. Ekenved, U. Haglund, and L. Olbe, "Effect of omeprazole-a gastric proton pump inhibitor-on 
pentagastrin stimulated acid secretion in man," Gut, vol. 24, no. 4, pp. 270-276, 1983.

[3] M. J. Kendall, "Review article: esomeprazole - the first proton pump inhibitor to be developed as an isomer," Alimentary Pharmacology \& Therapeutics, vol. 17, Supplement 1, pp. 1-4, 2003.

[4] A. A. Al-Badr, "Omeprazole," in Profiles of drug substances, excipients and related methodology, H. G. Brittain, Ed., vol. 35, pp. 151-262, Elsevier, Amsterdam, 2008.

[5] A. Gustavsson, K. Kjellbom, and I. Ymén, "Omeprazole sodium salt," Patent: US 6.207.188 B1, 2001.

[6] M. Reddy, S. Eswaraiah, V. V. N. K. V. Raju et al., "Crystalline form $\mathrm{C}$ of omeprazole sodium and the related process of its preparation, a crystalline form $\mathrm{D}$ of omeprazole sodium and the related process of its preparation, and a process for preparation of crystalline form a of omeprazole sodium," Patent: US 2004/0224987, 2004.

[7] L. Vranicar Savanovic, Z. Ham, and J. Rzen, "Crystalline solvate of omeprazole sodium,” Patent: US 2009/0221646, 2009.

[8] N. Markovic, S. Agntovic-Kustrin, B. Glass, and C. A. Prestidge, "Physical and thermal characterisation of chiral omeprazole sodium salts," Journal of Pharmaceutical and Biomedical Analysis, vol. 42, no. 1, pp. 25-31, 2006.

[9] N. Furuyama, S. Hasegawa, T. Hamaura et al., "Evaluation of solid dispersions on a molecular level by the Raman mapping technique," International Journal of Pharmaceutics, vol. 361, no. 1-2, pp. 12-18, 2008.

[10] E. Widjaja and R. K. Hong Seah, "Application of Raman microscopy and band-target entropy minimization to identify minor components in model pharmaceutical tablets," Journal of Pharmaceutical and Biomedical Analysis, vol. 46, no. 2, pp. 274-281, 2008.

[11] D. Clark and S. Šašić, "Chemical images: technical approaches and issues," Cytometry Part A, vol. 69A, no. 8, pp. 815-824, 2006.

[12] A. E. Brändström, “Omeprazole salts,” Patent: EP 0124495 B1, 1987.

[13] N. H. Milac, A. Copar, B. Podobnik et al., "Crystalline form of omeprazole,” Patent: US 7.553.856 B2, 2009.

[14] N. Kumar, T. Sharma, and B. Vijayaraghavan, "Novel amorphous form of omeprazole salts," Patent: WO 01/87831 A2, 2002.

[15] G. Kresse and J. Hafner, "Ab initio molecular dynamics for liquid metals,” Physical Review B, vol. 47, p. 558, 1993.

[16] G. Kresse and J. Furthmuller, "Efficient iterative schemes for $a b$ initio total-energy calculations using a plane-wave basis set," Physical Review B, vol. 54, article 11169, 1996.

[17] G. Kresse and D. Joubert, "From ultrasoft pseudopotentials to the projector augmented-wave method," Physical Review B, vol. 59, p. 1758, 1999.

[18] J. P. Perdew, K. Burke, and M. Ernzerhof, "Generalized gradient approximation made simple," Physical Review Letters, vol. 77, p. 3865, 1996, Erratum Phys. Rev. Lett., vol. 78, pp. 1396, 1997.

[19] H. J. Monkhorst and J. D. Pack, "Special points for Brillouinzone integrations," Physical Review B, vol. 13, p. 5188, 1976.

[20] P. M. Bhatt and G. R. Desiraju, "Tautomeric polymorphism in omeprazole," Chemical Communications, vol. 20, pp. 2057-2059, 2007.
[21] D. M. Wood and A. Zunger, "A new method for diagonalising large matrices," Journal of Physics A: Mathematical and General, vol. 18, no. 9, p. 1343, 1985.

[22] S. Baroni, S. de Gironcoli, and A. del Corso, "Phonons and related crystal properties from density-functional perturbation theory," Reviews of Modern Physics, vol. 73, p. 515, 2001.

[23] F. S. Murakami, A. P. Cruz, R. N. Pereira, B. R. Valente, and M. A. S. Silva, "Development and validation of a RP-HPLC method to quantify omeprazole in delayed release tablets," Journal of Liquid Chromatography \& Related Technologies, vol. 30, no. 1, pp. 113-121, 2007.

[24] S. Martindale, The Complete Drug Reference, Pharmaceutical Press, London, Thomson Micromedex, Greenwood Village, 33 edition, 2002.

[25] M. Dellagreca, M. R. Iesce, L. Previtera, M. Rubino, F. Temussi, and M. Brigante, "Degradation of lansoprazole and omeprazole in the aquatic environment," Chemosphere, vol. 63, no. 7, pp. 1087-1093, 2006.

[26] R. M. Claramunt, C. López, and J. Elguero, "The structure of omeprazole in the solid state: a ${ }^{13} \mathrm{C}$ and ${ }^{15} \mathrm{~N}$ NMR/CPMAS study," ARKIVOC, vol. 2006, no. 5, pp. 5-11, 2006.

[27] M. A. Palafox, "Scaling factors for the prediction of vibrational spectra. I. Benzene molecule," International Journal of Quantum Chemistry, vol. 77, no. 3, pp. 661-684, 2000.

[28] M. A. Morsy, M. A. Al-Khalidi, and A. Suwaiyan, "Normal vibrational mode analysis and assignment of benzimidazole by ab initio and density functional calculations and polarized infrared and Raman spectroscopy," The Journal of Physical Chemistry A, vol. 106, no. 40, pp. 9196-9203, 2002.

[29] P. J. Larkin, IR and Raman Spectroscopy Principles and Spectral Interpretation, Elsevier, Waltham, MA, USA, 2011.

[30] K. C. Medhi, "Vibrational spectra and thermodynamic functions of 2-methoxypyridine and 2-methoxy- $d_{3}$-pyridine," Bulletin of the Chemical Society of Japan, vol. 57, no. 1, pp. 261-266, 1984. 

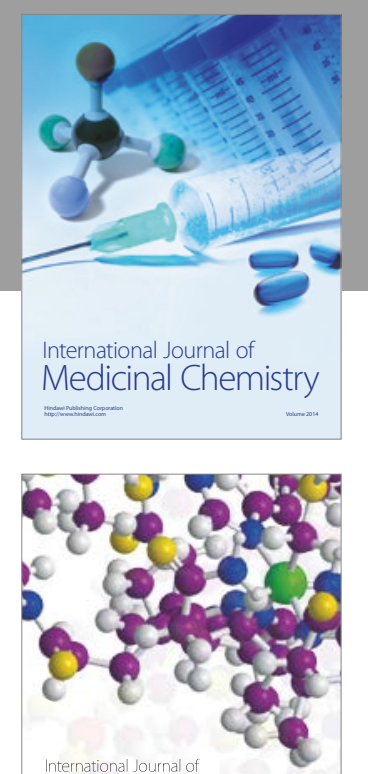

Carbohydrate Chemistry

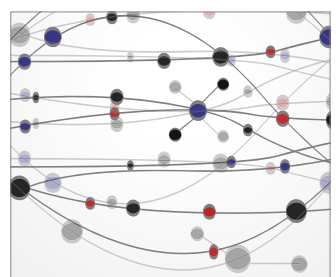

The Scientific World Journal
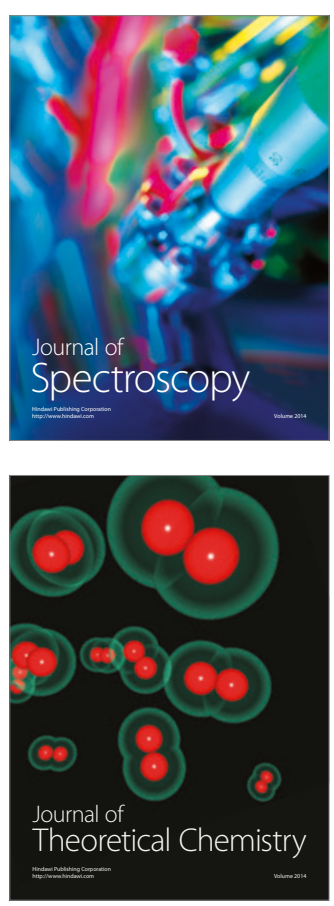
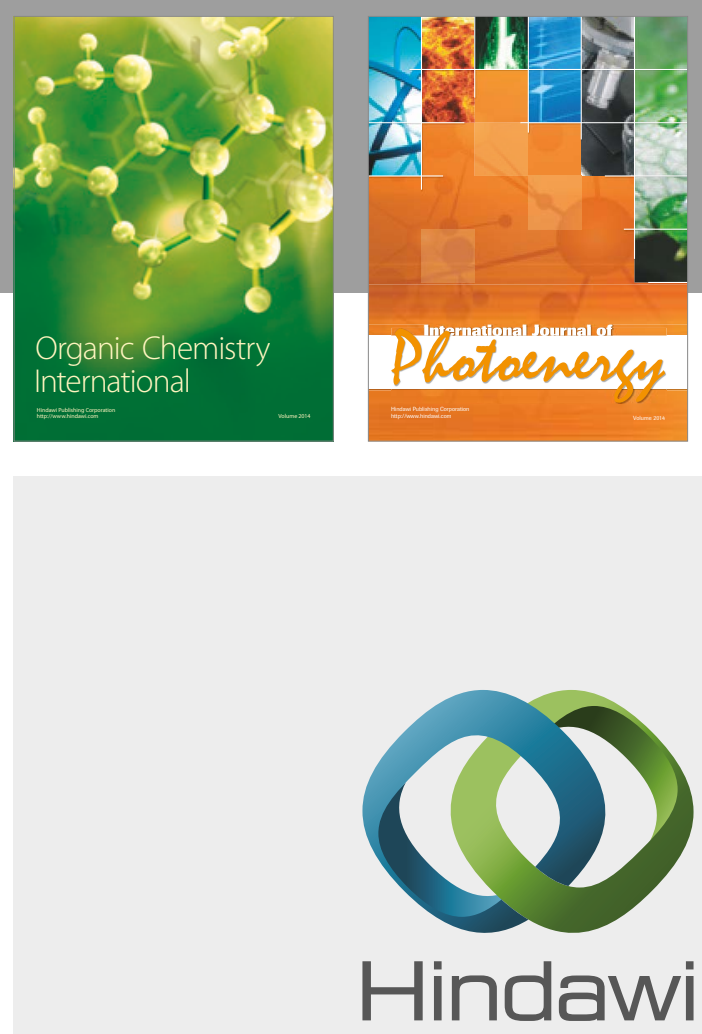

Submit your manuscripts at

https://www.hindawi.com

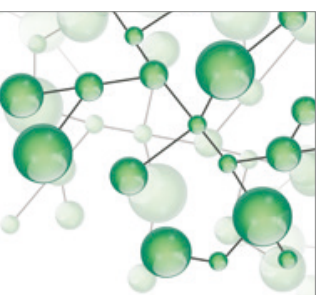

International Journal of

Inorganic Chemistry

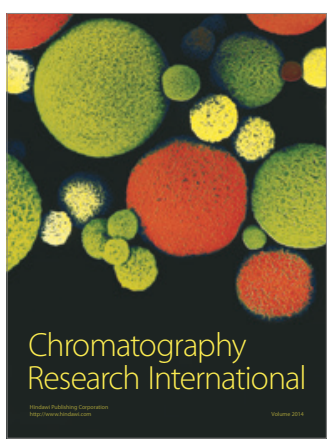

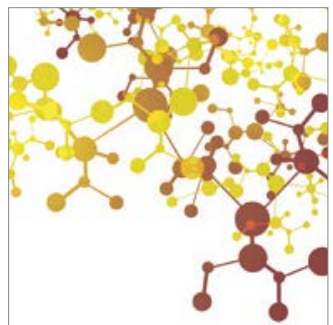

Applied Chemistry
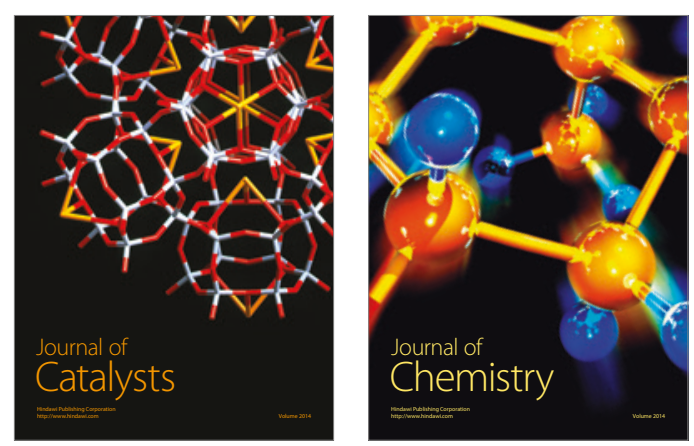
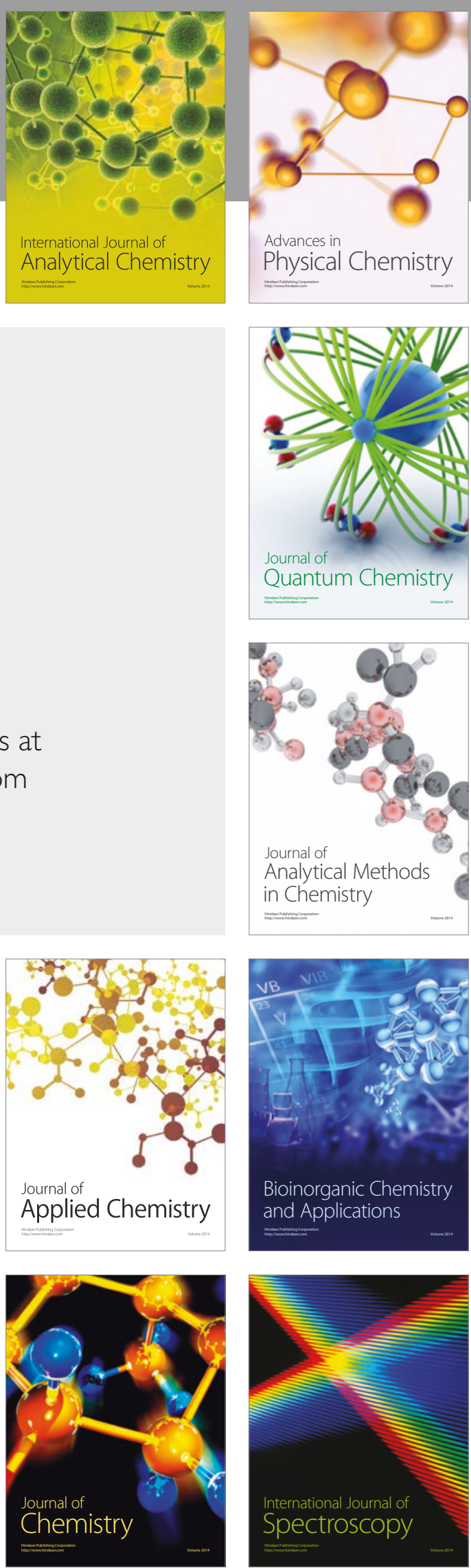